Journal of Advanced Research in Fluid Mechanics and Thermal Sciences

\title{
Characterization the Thermal Degradation E Kinetic of Unsaturated Polyester and Polyester/Silica Nanoparticles Composites by TGA and DSC Analysis
}

\author{
Ahmed Jadah Farhan ${ }^{1, *}$ \\ 1 Department of Physics, College of Science, University of Wasit, Kut, Wasit, Iraq
}

\section{ARTICLE INFO}

\section{Article history:}

Received 1 November 2019

Received in revised form 10 December 2019

Accepted 10 December 2019

Available online 30 April 2020

\section{ABSTRACT}

The development of polymer nanocomposites is rapidly emerging as a multidisciplinary research field with results that could broaden the applications of polymers to many different industries. The nanocomposites were prepared from unsaturated polyester (UPE) mixed with a different percentage $(10,20$, and $30 \%)$ of silica nanoparticles. TGA and DSC curves were obtained from the thermal degradation computed by using CoastRedfern technique. Kinetic and thermodynamic parameters were studied for all specimens were presented a good linear correlation coefficient close to unity using Minitab 16. Experimental work was showed that the degradation of composites that obtained from thermal gravimetric analysis was slower than the resin. Also, the decomposition under the oxidative environment was much faster than the inert environment. The enhancement of stability was attributed to silica content.

Keywords:

Thermal decomposition; Thermo gravimetric analysis; Unsaturated polyester composites; Silica nanoparticles

Copyright @ 2020 PENERBIT AKADEMIA BARU - All rights reserved

\section{Introduction}

Poly condensation polymers considered very practical in several usages due to its price and easily fabricated, good mechanical property, and higher corrosion property [1]. It is widely employed especially in the area of coating, electrical application, fabrication parts of automotive, and construction fields [2-4].

Kinetic parameter and thermodynamic prosperities and thermal stability determined by utilizing TGA and DSC which gives a very clear idea about the structure of the polymers and the behaviour of various composites under severe heat [5-8]. Oxidative and thermal decomposition of polymers and composite occurs usually at higher temperature by the elimination of molecules along the polymer chain followed by random scission of the backbone chain, however these changes produce more

\footnotetext{
* Corresponding author.

E-mail address: kutpc19@yahoo.com (Ahmed Jadah Farhan)
}

https://doi.org/10.37934/arfmts.71.1.1020 
volatiles, gases and eventually all the polymer convert to high molecules of poly nuclear ring so called chars [9-12]. However, polyester decomposition occurs in two stages, in the first stage the degradation of the backbone of the main chain occurs by ester change and hydrogen elimination and finally coverts to volatiles, gases, and char because of its strong hydrogen bond prevent it from melting in the second stage [13-15].

Recently the kinetic of decomposition have been studied by many researchers, however they concentrated on constant decomposition rate, activation energy and thermodynamic properties of different polymers and its different composite and they showed the enhancement in thermal stability of composites by using different inclusions [16-18].

\section{Kinetic Theory}

The Coats-Redfern method is a multi-heating rate application of the Coats-Redfern equation [19] has been applied to study the kinetics of the decomposition of the polymer and its composite.

$\ln \left[\left\{-\ln (1-\alpha) / T^{2}\right\}\right]=\ln \left(A_{\circ} R / \beta E_{a}\right)\left\{1-\left(2 R T / E_{a}\right)\right\}-\left(E_{a} / R T\right)$

where

$\alpha=$ The extent of the reaction

$\beta=$ The constant heating rate

$A_{o}=$ The frequency factor

$\mathrm{R}=$ The universal gas constant

$\mathrm{T}=$ The decomposition temperature

$E_{a}=$ The activation energy

By plotting $\ln \left[\left\{-\ln (1-\alpha) / T^{2}\right\}\right]$ against $1 / T$ for each heating rate gives a family of straight lines of slope $E / R$ Frequency factor directly determined from $Y$ axis intercept by substituting values of activation energies:

Intercept $=\ln \left(A_{\circ} R / \beta E_{a}\right)\left\{1-\left(2 R T / E_{a}\right)\right\}$

\section{Results and Discussion}

\subsection{Composite Fabrication}

The materials employed to fabricate the nano composites are unsaturated polyester resin (UPE) as a matrex. It is a liquid with moderate viscosity which can be cured to the solid state by adding (Methyle Ethyle Keton Peroxide, MEKP) as a hardener, while cobalt octoate acts as a catalyst to accelerate the solidification process. The percentage of the hardener to the resin is $(2 \%)$ while it is $(0.5 \%)$ for the accelerator. Desirable physical properties, easily handled, quickly cured and stable dimensions after solidification. The properties of unsaturated polyester resin are given in Table 1. Hardener: is a chemical material, which is added to thermosetting resin for the purpose to cause curing or hardening. The terms hardener and curing agent are used interchangeably. Note that these can differ from catalysts, promoters, and accelerators. Curing: To change the physical properties of the material (usually from a liquid to a solid) by chemical reaction, by the action of heat and catalysts, alone or in combination, with or without pressure. accelerator: A chemical used to speed up a reaction or cure. The term accelerator is often used interchangeably with the term promoter [20]. Silica nano particles with a particle size of $100 \mathrm{~nm}$ were used as commercial filler. The chemical 
composition of nano silica is given in Table 2. Atomic force microscopy (AFM) was used (CSPM scanning probe microscope) to measure the average particles size of nano silica, the particles size distribution is shown in Figure 1.

Samples of the polymer and nano composites at different Silica content $(10,20$, and $30 \%)$ are fabricated by cast moulding. All content mixed thoroughly before casting, then the samples left at ambient temperature for $24 \mathrm{hr}$, and then cured, the specimens were left for $2 \mathrm{hr}$ in an oven at temperature $60^{\circ} \mathrm{C}$.

Table 1

Typical properties of unsaturated polyester resin [21]

\begin{tabular}{ll}
\hline Property & Unsaturated Polyester (UPE) \\
\hline Density (gm/cm3) & $1.05-1.4$ \\
Tensile strength (MPa) & $45-103$ \\
Tensile modulus (GPa) & $1.3-4.5$ \\
Cure shrinkage \% & $5-12$ \\
$\mathrm{Tg}(\mathrm{k})$ & 340 \\
\hline
\end{tabular}

Table 2

Chemical composition for the silica nanoparticles

\begin{tabular}{lllllllllll}
\hline \multirow{2}{*}{ Material } & \multicolumn{2}{l}{ Components \% } & & & & & & \\
& $\mathrm{SiO}_{2}$ & $\mathrm{Al}_{2} \mathrm{O}_{3}$ & $\mathrm{Fe}_{2} \mathrm{O}_{3}$ & $\mathrm{CaO}$ & $\mathrm{MgO}$ & $\mathrm{Na}_{2} \mathrm{O}$ & $\mathrm{K}_{2} \mathrm{O}$ & $\mathrm{MnO}$ & $\mathrm{Pb}_{2} \mathrm{O}_{3}$ & $\mathrm{Cu}_{2} \mathrm{O}$ \\
\hline Silica & 0.96 & 0.14 & 2.16 & 53.67 & 0.84 & 0.006 & 0.006 & 0.019 & 0.013 & 0.005 \\
\hline
\end{tabular}
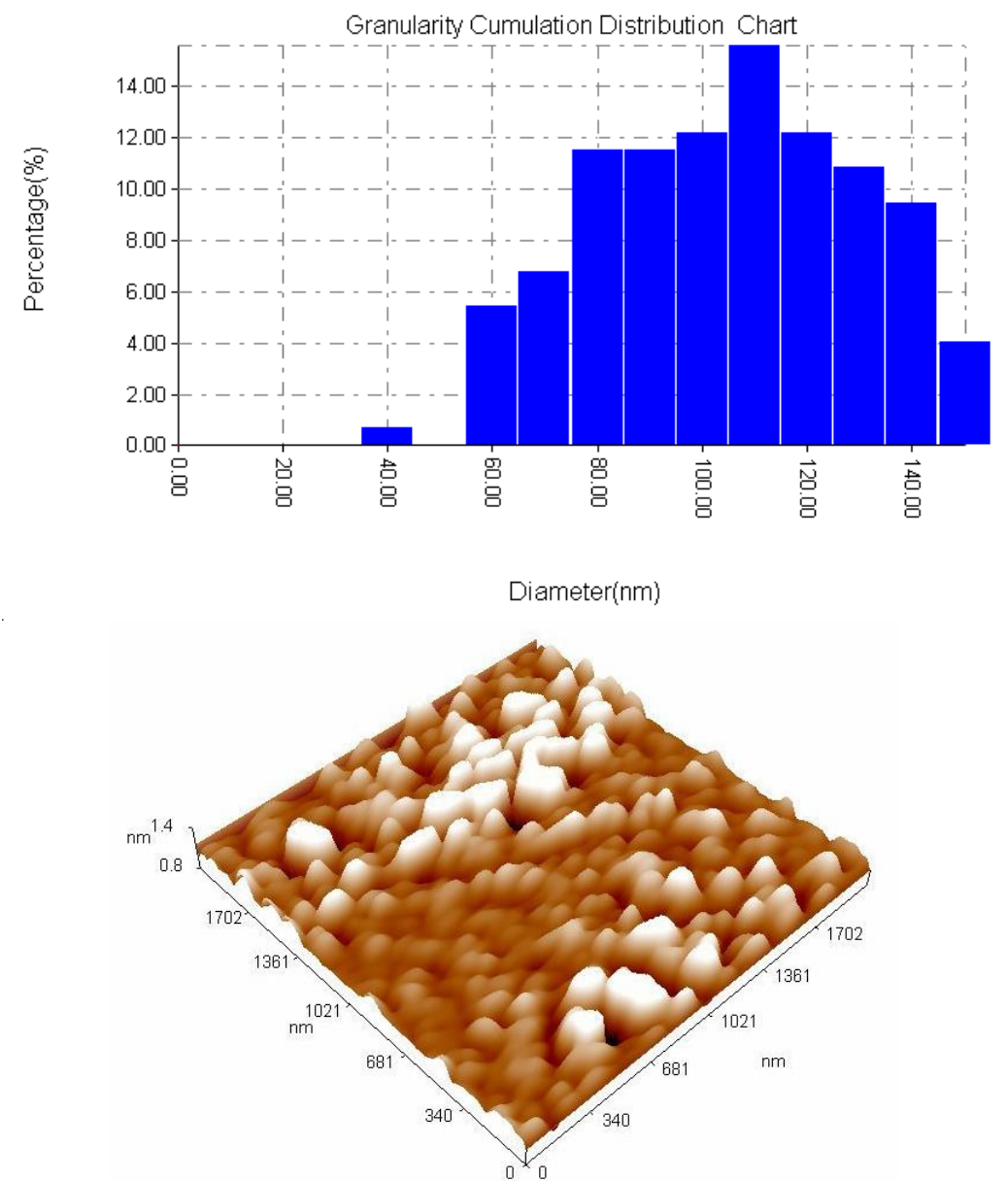

Fig. 1. AFM of silica nanoparticles 


\subsection{Thermogravimetric Analysis}

TGA and DSC is an important tool to study the kinetic of thermal decomposition, and to describe the way were the polymer degrade and to determine the melting point and glass transition temperature and to study the thermodynamics of thermal and to demonstrate the stability. Thermal decomposition carried out at constant heating rate of $10{ }^{\circ} \mathrm{C} / \mathrm{min}$ in inert atmosphere between 35 $650^{\circ} \mathrm{C}$.

Figure 2 shows TGA and DSC profiles for pure polyester resin under oxidative agent, it can be seen the polymer start in losing its weight initially about $6 \mathrm{wt} \%$ at temperature between $190{ }^{\circ} \mathrm{C}$ and 300 ${ }^{\circ} \mathrm{C}$ then start losing major weight $60.9 \mathrm{wt} \%$ between $300{ }^{\circ} \mathrm{C}$ and $430{ }^{\circ} \mathrm{C}$, however this represents the first stage degradation, while the second stage starts $405{ }^{\circ} \mathrm{C}$ till $462{ }^{\circ} \mathrm{C}$ with weight lose 9.97 wt $\%$ then the char start to gasify. From DSC profile observed two peaks which represent exothermic decomposition, first small peak at $407.3 \mathrm{C}^{\circ}$ which represent the backbone scission followed with a big peak at $478.9^{\circ} \mathrm{C}$ which represent the gasification of char.

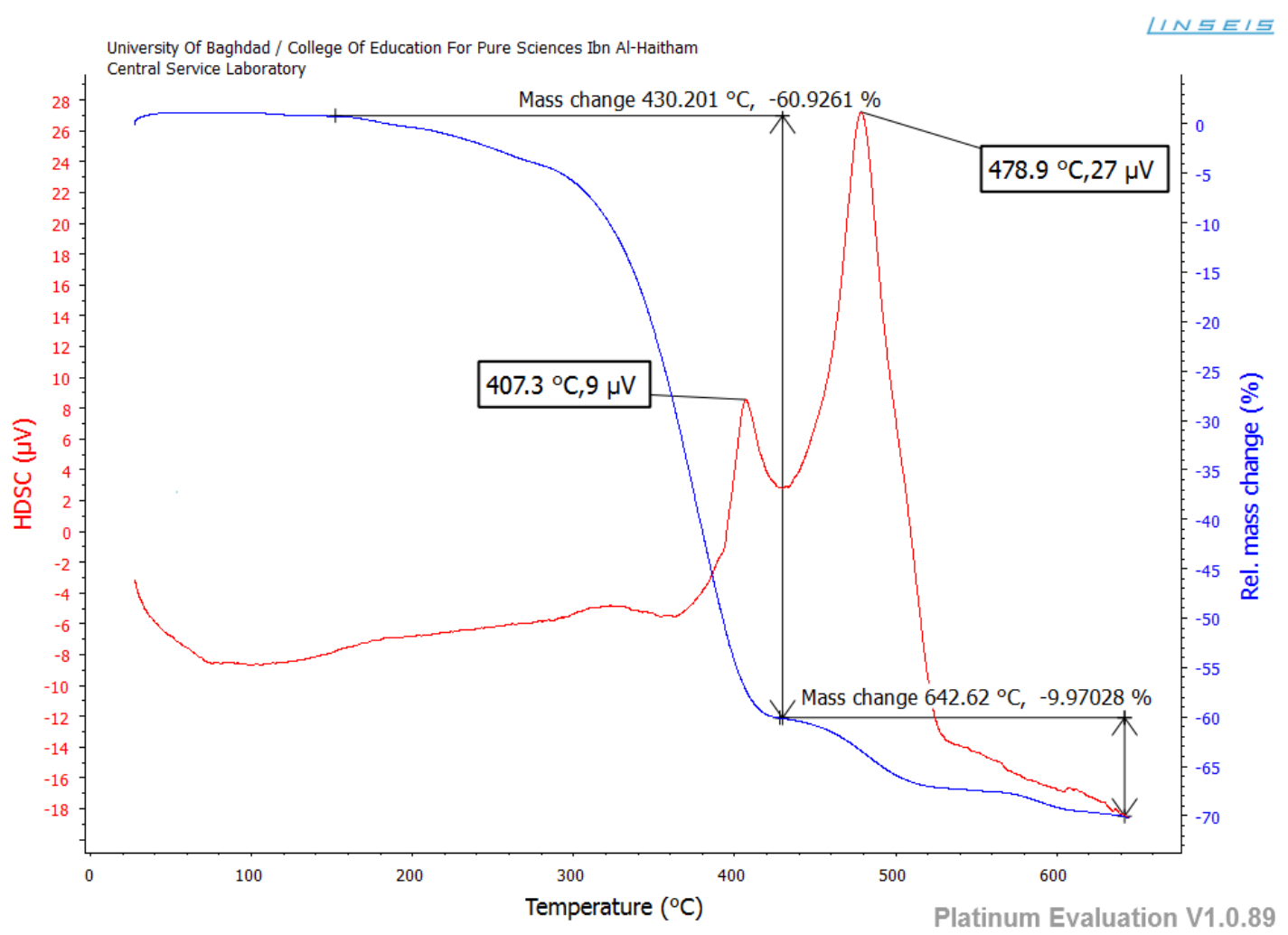

Fig. 2. TGA and DSC curve for pure polymer under oxidative environment 
Figure 3 shows the profiles of pure polyester under inert conditions were initial lose weight starts $237^{\circ} \mathrm{C}$ till $310^{\circ} \mathrm{C}$ with weight lose $5.5 \mathrm{wt} \%$ followed by the first stage with weight lost $73.2 \mathrm{wt} \%$ between temperature range $310^{\circ} \mathrm{C}$ to $437^{\circ} \mathrm{C}$ and the second stage lose $18.8 \mathrm{wt} \%$ which ends at 641.8 ${ }^{\circ} \mathrm{C}$, the DSC profile also showed two peaks first at $415^{\circ} \mathrm{C}$ and the second one at $435{ }^{\circ} \mathrm{C}$. Table 3 shows the mass loss of polyester pure and with various weight percent of Silica content. However, there is a difference in activation energy of oxidative and non-oxidative agent. In oxidative the activation energy is much lower than non-oxidative as shown in Table 4. This is because oxygen enhance the decomposition, consequently reducing activation energies of decomposition.

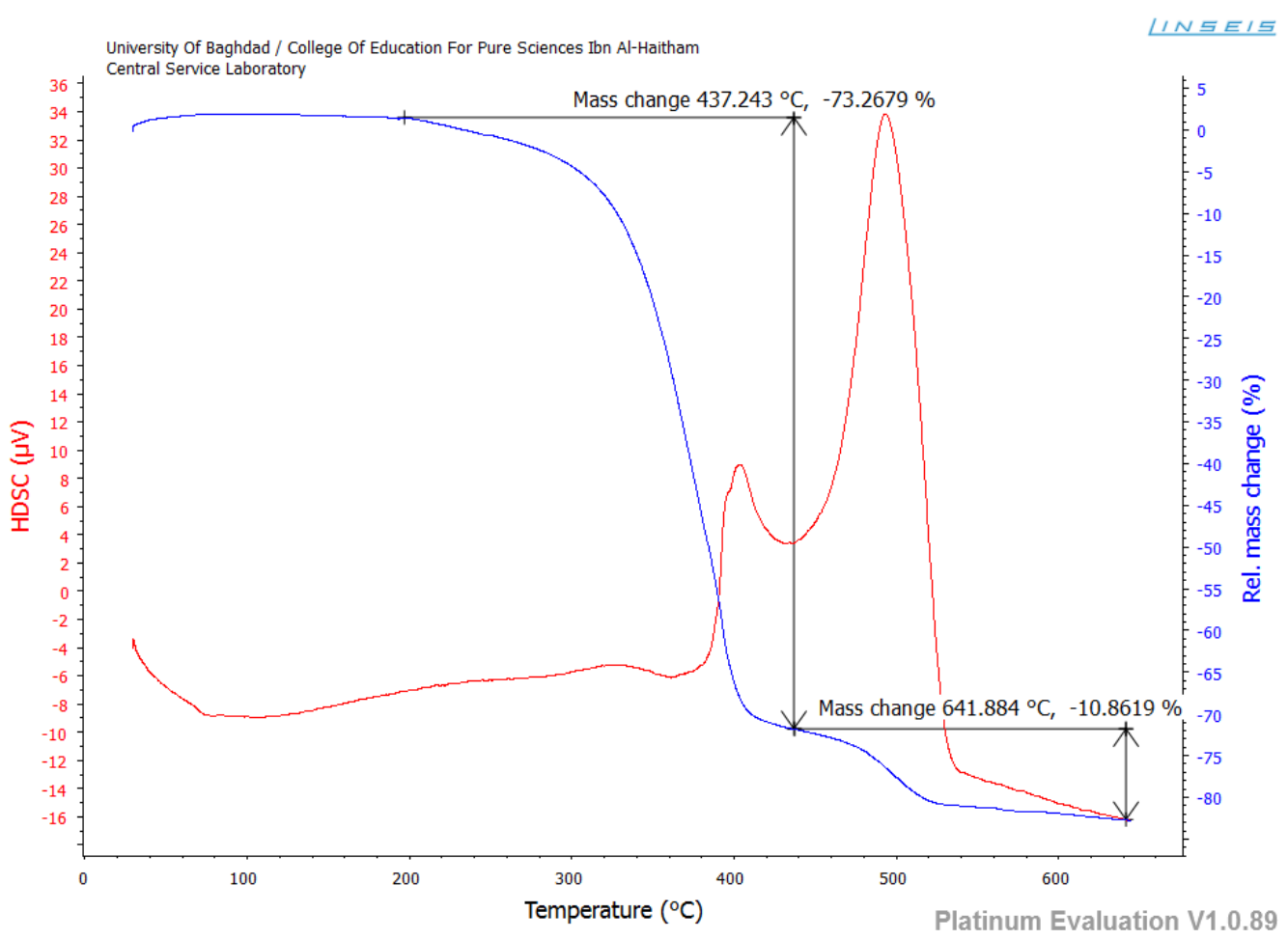

Fig. 3. TGA and DSC curve for pure polymer under inert environment

\section{Table 3}

Mass lost during decomposition for unsaturated poly ester and its composite

\begin{tabular}{lllll}
\hline The samples & environment & loss first stage & loss second stage & Total mass loss \\
\hline UPE pure & oxidative & $430.2^{\circ} \mathrm{C}, 60.92 \%$ & $642.6^{\circ} \mathrm{C}, 9.97 \%$ & $70.89 \%$ \\
UPE pure & inert & $437.2^{\circ} \mathrm{C}, 73.26 \%$ & $641.8^{\circ} \mathrm{C}, 10.86 \%$ & $84.12 \%$ \\
UPE $+10 \%$ Silica & inert & $438.2^{\circ} \mathrm{C}, 80.73 \%$ & $643.9^{\circ} \mathrm{C}, 11.34 \%$ & $92.07 \%$ \\
UPE $+20 \%$ Silica & inert & $435.9^{\circ} \mathrm{C}, 82.74 \%$ & $643.7^{\circ} \mathrm{C}, 15.05 \%$ & $97.79 \%$ \\
UPE $+30 \%$ Silica & inert & $443.8^{\circ} \mathrm{C}, 72.51 \%$ & $643.2^{\circ} \mathrm{C}, 12.49 \%$ & $85.00 \%$ \\
\hline
\end{tabular}




\section{Table 4}

Kinetics data of non-isothermal degradation of UPE and its composites according to Coats-Redfern method

\begin{tabular}{llllll}
\hline \multirow{2}{*}{ The samples } & \multirow{2}{*}{ environment } & $\begin{array}{l}\text { Peak Temperature, } \\
T_{\mathrm{p}}(\mathrm{K})\end{array}$ & $\begin{array}{l}\text { Activation Energy, } \\
\mathrm{E}_{\mathrm{a}}(\mathrm{kj} / \mathrm{mol})\end{array}$ & $\begin{array}{l}\text { Reaction rate } \\
\text { constant, } \mathrm{A}_{\mathrm{o}}\left(\mathrm{S}^{-1}\right)\end{array}$ & $\mathrm{R}^{2}$ \\
\hline UPE pure & Oxidative & 652 & 78.0680 & $0.3164 \times 10^{4}$ & $99.1 \%$ \\
UPE pure & Inert & 660 & 99.0030 & $22.260 \times 10^{4}$ & $99.7 \%$ \\
UPE +10\% Silica & Inert & 665 & 100.358 & $31.708 \times 10^{4}$ & $99.6 \%$ \\
UPE +20\% Silica & Inert & 656 & 111.382 & $308.222 \times 10^{4}$ & $98.7 \%$ \\
UPE +30\% Silica & Inert & 661 & 117.934 & $835.108 \times 10^{4}$ & $99.6 \%$ \\
\hline
\end{tabular}

The effect of addition Silica filler at different percentages are shown in Figure 4, Figure 5 and Figure 6. However it can be seen the thermal stability increases with increasing Silica content Figure 6 is differ completely than Figure 2 and Figure 3 especially at the initial stage which start $327 \mathrm{C}$ with initial mass loss of composite $5.5 \mathrm{wt} \%$ followed with first stage decomposition which ends at $443^{\circ} \mathrm{C}$ with mass loss 72.5 wt\%, while the stage mass loss is 12.49 wt\% which is considered much lower comparing with pure polyester Figure 3. DSC profile showed two peaks, the first appeared at $399^{\circ} \mathrm{C}$, while the second at $508.2{ }^{\circ} \mathrm{C}$ which is considered much higher comparing with Figure 3 , this is because of increasing thermal stability.

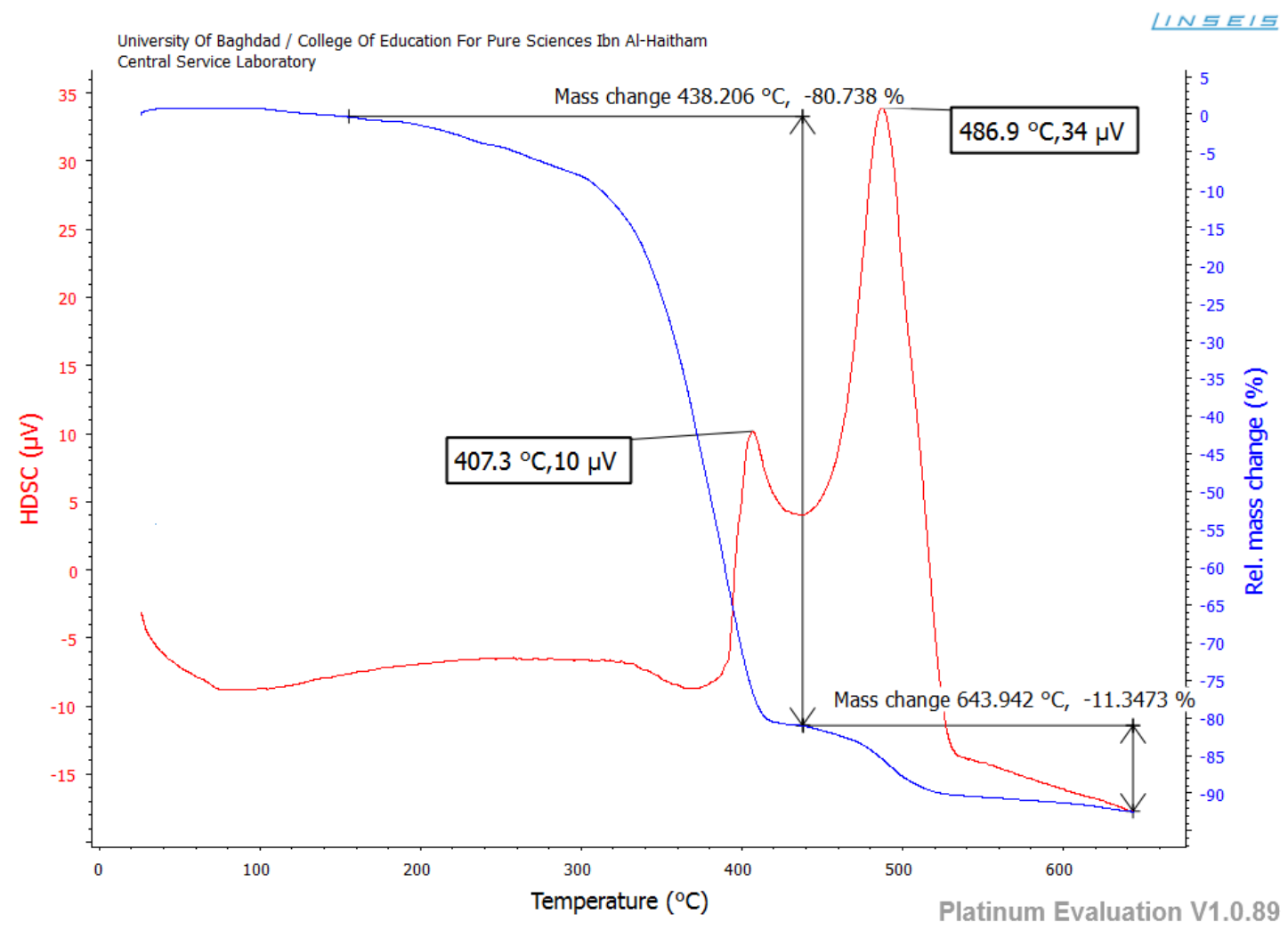

Fig. 4. TGA and DSC curve for unsaturated polyester/Silica $10 \mathrm{wt} \%$ 


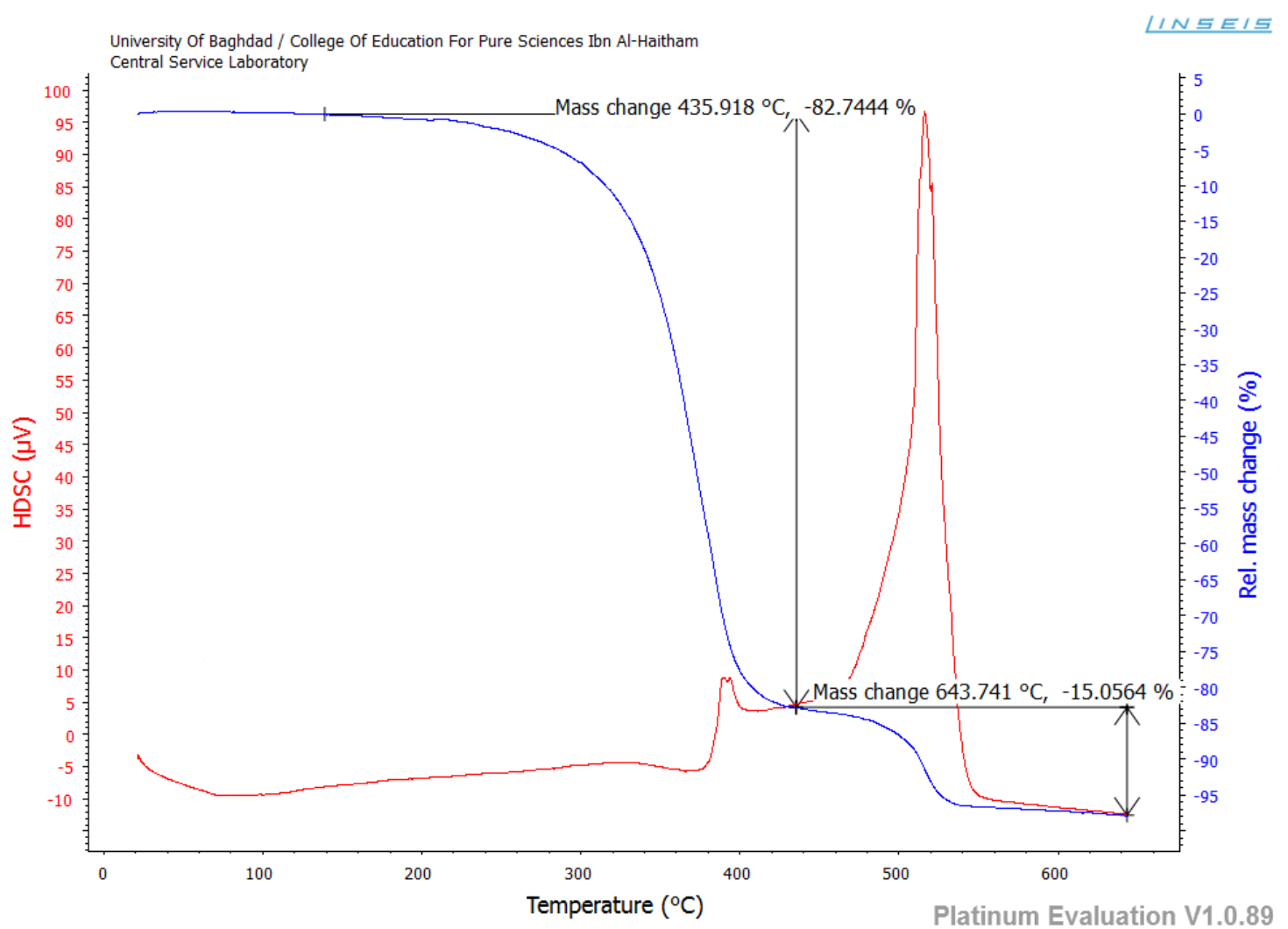

Fig. 5. TGA and DSC curve for unsaturated polyester/Silica $20 \mathrm{wt} \%$

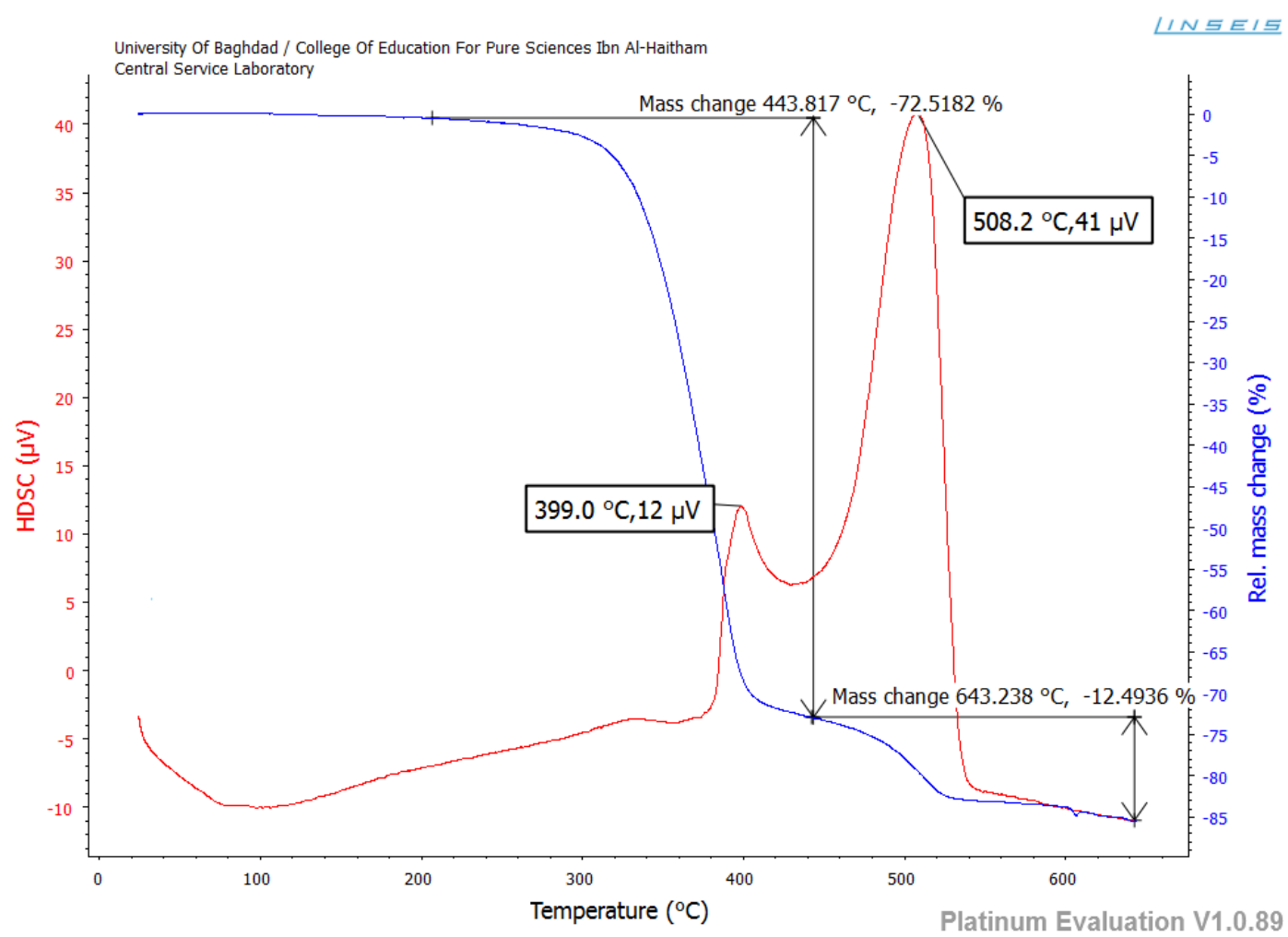

Fig. 6. TGA and DSC curve for unsaturated polyester/Silica $30 \mathrm{wt} \%$. 
Applying the Coast-Redfern method as shown in Figure 7 a typical plot of $\ln \left(-\ln (1-\alpha) / T^{2}\right)$ against $(1 / T)$ for oxidative thermal decomposition pure unsaturated polyester, for first order reaction.

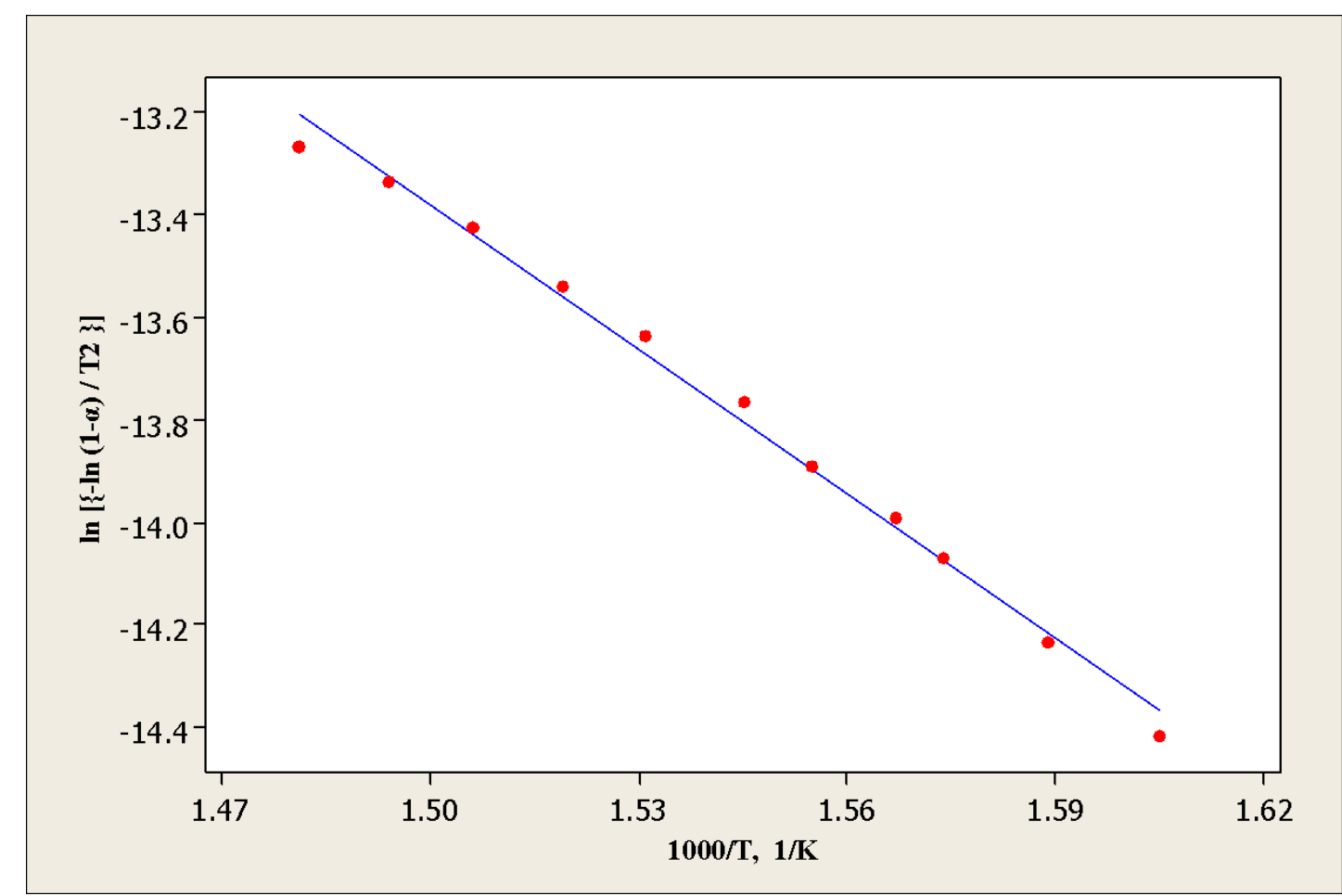

Fig. 7. A plot of oxidative thermal decomposition utilizing Coast-Redfern method

The method applied for pure unsaturated polyester and its composites at different Silica content is shown in Figure 8.

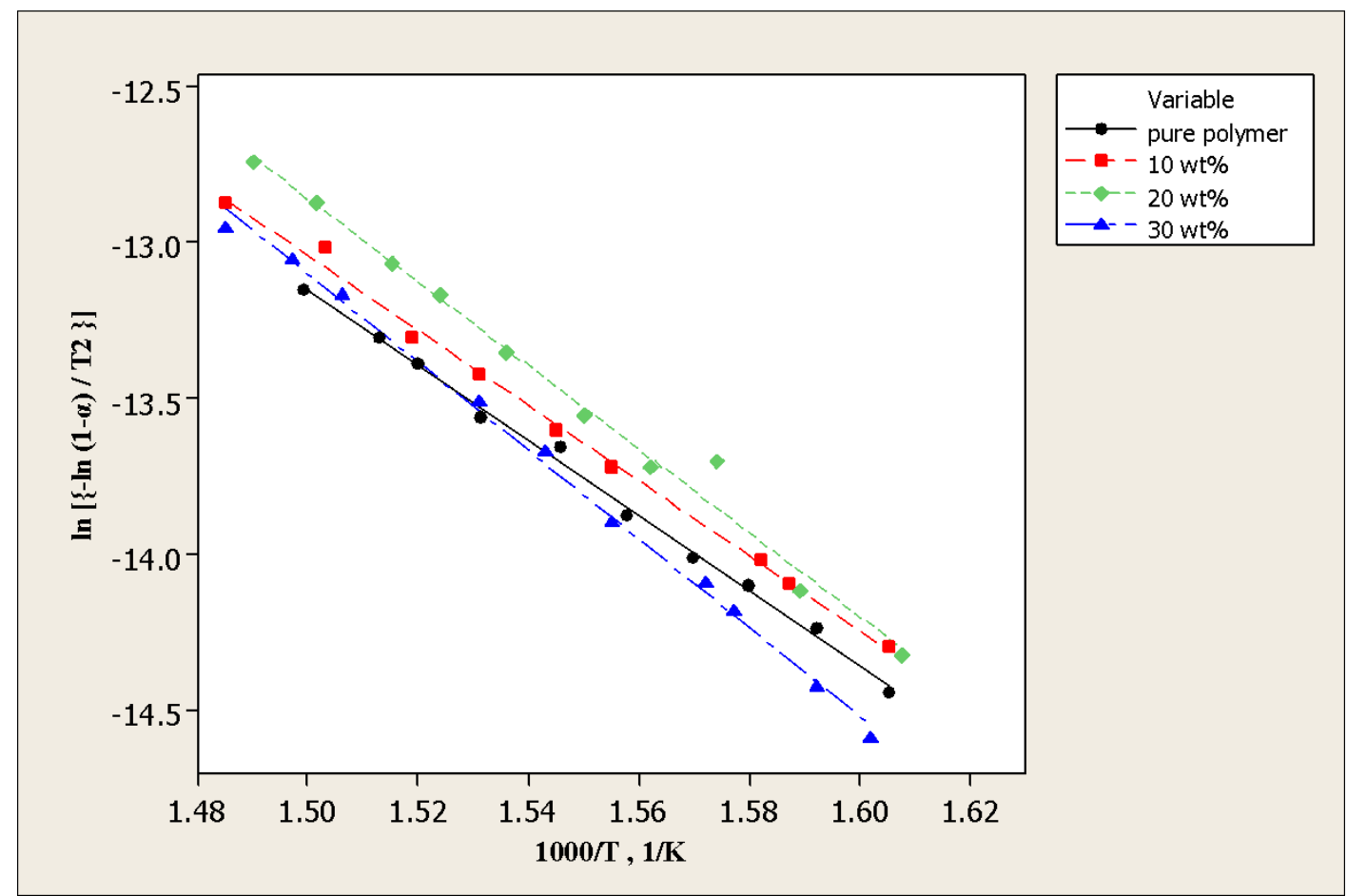

Fig. 8. A plot of non-oxidative thermal decomposition utilizing Coast-Redfern method 
The thermodynamic properties were estimated by the following equations [22-23]:

$\Delta \mathrm{H}=\mathrm{E}-\mathrm{R} \mathrm{T}_{\text {peak }}$

$\Delta S=R\left[\ln \left(h A_{o} / k_{b} T_{\text {peak }}\right)-1\right]$

$\Delta G=\Delta H-T_{\text {peak }} \Delta S$

where $\Delta H$ is activation enthalpy, $\Delta S$ is activation entropy, $\Delta G$ is activation free energy of decomposition, $T_{\text {peak }}$ is maximum peak temperature, $\mathrm{h}$ is Plank constant and $\mathrm{k}_{\mathrm{b}}$ is Boltzmann constant. Table 5 shows the thermodynamics property of pure unsaturated polyester and its composites according to Coast-Redfern method used in determining kinetic data.

\section{Table 5}

Thermodynamics property of UPE/Silica composites

\begin{tabular}{llllll}
\hline The samples & Environment & $\mathrm{T}_{\text {peak }},(\mathrm{K})$ & $\Delta \mathrm{H}, \mathrm{KJ} / \mathrm{mol}$ & $-\Delta \mathrm{S}, \mathrm{J} / \mathrm{mol}$ & $\Delta \mathrm{G}, \mathrm{kJ} / \mathrm{mol}$ \\
\hline USP Pure & Oxidative & 652 & 72.647 & 192.721 & 198.301 \\
USP Pure & Inert & 660 & 93.515 & 157.459 & 197.438 \\
USP+10\% Silica & Inert & 665 & 94.829 & 154.758 & 197.743 \\
USP+20\% Silica & Inert & 656 & 105.928 & 135.559 & 194.854 \\
USP+30\% Silica & Inert & 661 & 112.438 & 127.334 & 113.496 \\
\hline
\end{tabular}

Figure 9 shows there is a linear relationship between activation energy, $E_{a}$ and Entropy, $\Delta S$ with accuracy $R^{2}=99.3 \%$ [24-25]. Table 5 shows that the activation energy increases with increasing entropy and the positive values of internal energy means the degradation process is not spontaneous [26].

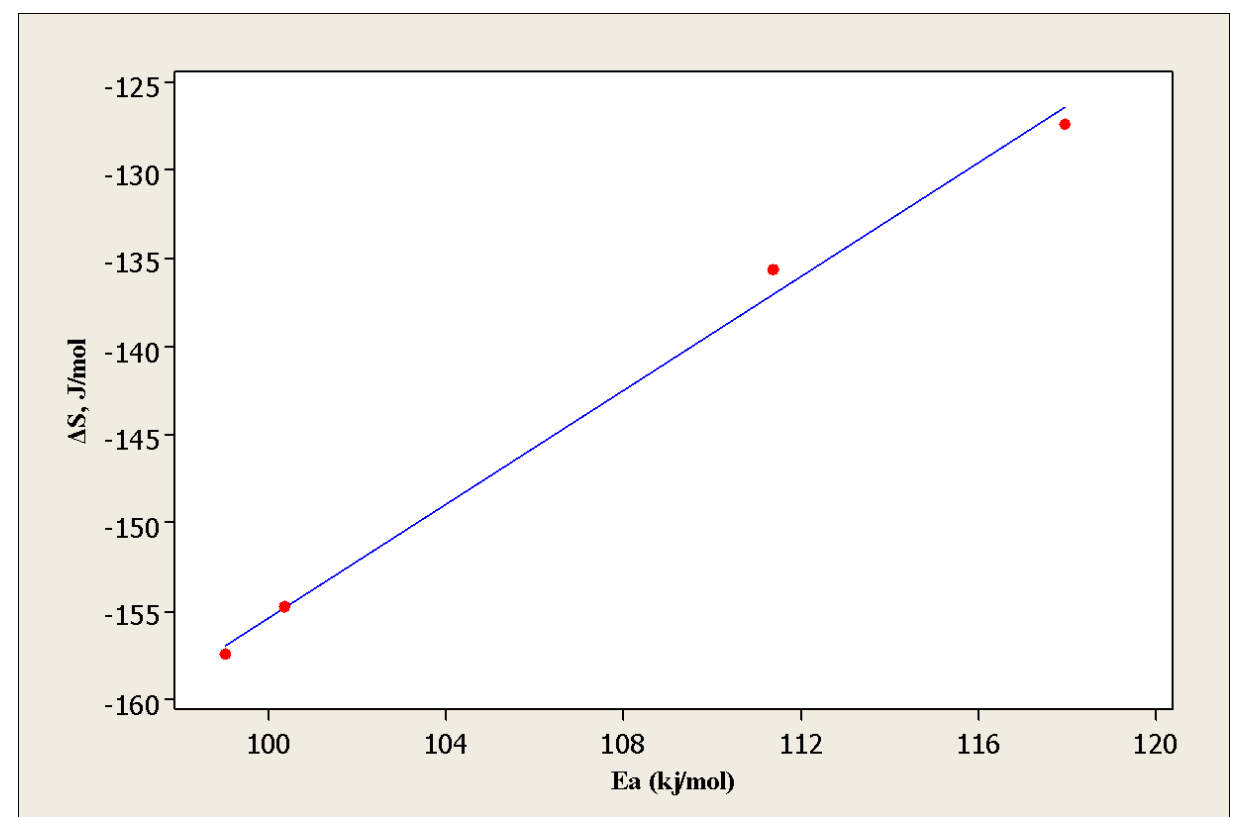

Fig. 9. Plot of Entropy against Activation energy for thermal decomposition of UPE and its composite 


\section{Conclusions}

Thermal decomposition of unsaturated polyester and silica nanocomposite has been studied by TGA and DSC technique. UPE and UPE/Silica were degraded in two stages and almost $94 \%$ of original mass was decomposed into volatiles and char. The activation energy and the entropy of the composite materials were higher than the pure UPE in oxidation and inert environment, the reason being that the presence of silica powder increased the thermal stability. DSC profile was showed there were a shift of decomposition peaks towards right side because of enhancement of thermal stability for composite as compared with pure UPE.

\section{References}

[1] Atta, Ayman M., Sayed I. Elnagdy, Manar E. Abdel-Raouf, Shimaa M. Elsaeed, and Abdel-Azim A. Abdel-Azim. "Compressive properties and curing behaviour of unsaturated polyester resins in the presence of vinyl ester resins derived from recycled poly (ethylene terephthalate)." Journal of Polymer Research 12, no. 5 (2005): 373-383. https://doi.org/10.1007/s10965-005-1638-3

[2] Selly J. and Mark, H. F. 1988 “Ecyclopedia of Polymer Science and Engineering”, Willey, New York, Vol.12, PP. (256290).

[3] Kramer H. “Unsaturated Polyester Resin”, Ullmanns Encyclopedia of Industrial Chemistry, Weinheim A21, (1992): 217.

[4] Giovanilton Ferrira da Silva, Fernando de Lima Camargo and Caio Glauco Sanchez. 2009 "Influence of the particle size in kinetic of pyrolysis of unsaturated polyester", $20^{\text {th }}$ International Congress of Mechanical Engineering, November 15-20, Gramado, RS, Brazil.

[5] Budrugeac, P., E. Segal, E. Stere, and Alice Luminita Petre. "Thermal degradation of a styrenated unsatured polyester resin." Journal of thermal analysis 46, no. 5 (1996): 1313-1324.

https://doi.org/10.1007/BF01979245

[6] Budrugeac, P., Alice Luminita Petre, and E. Segal. "Approximation of the TG curve through a temperature power series in order to evaluate the non-isothermal kinetic parameters of solid-gas decompositions and degradation." Thermochimica acta 275, no. 2 (1996): 193-213.

https://doi.org/10.1016/0040-6031(95)02725-4

[7] Budrugeac, P., and E. Segal. "Thermooxidative degradation of an unsaturated polyester resin." Journal of thermal analysis 49, no. 1 (1997): 183-191.

https://doi.org/10.1007/BF01987438

[8] Budrugeac P “Accelerated thermal ageing of nitrile-butadiene rubber under air pressure." Polymer Degradation and Stability 47, no. 1 (1995): 129-132. https://doi.org/10.1016/0141-3910(94)00101-D

[9] Regnier, N., and B. Mortaigne. "Analysis by pyrolysis/gas chromatography/mass spectrometry of glass fibre/vinylester thermal degradation products." Polymer degradation and stability 49, no. 3 (1995): 419-428. https://doi.org/10.1016/0141-3910(95)00129-A

[10] Bansal, Raj K., Jagjiwan Mittal, and Prakash Singh. "Thermal stability and degradation studies of polyester resins." Journal of applied polymer science 37, no. 7 (1989): 1901-1908. https://doi.org/10.1002/app.1989.070370713

[11] Gibson, A. G., and J. Hume. "Fire performance of composite panels for large marine structures." Plastics, Rubber \& Composites Processing and Appl. 3, no. 23 (1995): 175-183.

[12] Arii, Tadashi, Shoji Ichihara, Hideaki Nakagawa, and Nobuyuki Fujii. "A kinetic study of the thermal decomposition of polyesters by controlled-rate thermogravimetry." Thermochimica acta 319, no. 1-2 (1998): 139-149. https://doi.org/10.1016/S0040-6031(98)00414-6

[13] Mouritz, Adrian P., and Arthur Geoff Gibson. Fire properties of polymer composite materials. Vol. 143. Springer Science \& Business Media, 2007.

[14] Tagle L., Hand F. and Diaz. "Thermogravimetric analysis of polyesters derived from terephthalic, tetrachloroterephthalic and related diacids with bisphenol A." Thermochimica Acta 200, (1992): 281-291. https://doi.org/10.1016/0040-6031(92)85120-K

[15] Pielichowski, Krzysztof, and Ian Hamerton. "TGA/FTi. r. studies on the thermal stability of poly (vinyl chloride) blends with a novel colourant and stabilizer: 3-(2, 4-dichlorophenylazo)-9-(2, 3-epoxypropane) carbazole." Polymer 39, no. 1 (1998): 241-244. https://doi.org/10.1016/S0032-3861(97)00268-1 
[16] Al-Bayaty, Subhi A., and Ahmed Jadah Farhan. "Thermal decomposition kinetics unsaturated polyester and unsaturated polyester reinforcement by toner carbon nano powder (TCNP) composites." Int. J. Appl. Innovation Eng. Manag 4 (2015): 139-146.

[17] Ahmed A. Thamer, Hashim A. Yusr, and Najwa J. Jubier. "TGA, DSC, DTG Properties of Epoxy Polymer Nanocomposites by Adding Hexagonal Boron Nitride Nanoparticles." Journal of Engineering and Applied Sciences 14, no. 4 (2019): 567-574. https://doi.org/10.36478/jeasci.2019.567.574

[18] Ferreira, J. M., O. A. Z. Errajhi, and M. O. W. Richardson. "Thermogravimetric analysis of aluminised E-glass fibre reinforced unsaturated polyester composites." Polymer testing 25, no. 8 (2006): 1091-1094. https://doi.org/10.1016/i.polymertesting.2006.07.012

[19] Kim, Hee Taik, and Sea Cheon Oh. "Kinetics of thermal degradation of waste polypropylene and high-density polyethylene." Journal of Industrial and Engineering Chemistry 11, no. 5 (2005): 648-656.

[20] Charles, A. Handbook of plastics and elastomers. McGraw-Hill, 1975.

[21] Sperling, Leslie H. Introduction to physical polymer science. John Wiley \& Sons, 2005. https://doi.org/10.1002/0471757128

[22] Straszko, J., M. Olszak-Humienik, and J. Możejko. "Study of the mechanism and kinetic parameters of the thermal decomposition of cobalt sulphate hexahydrate." Journal of thermal analysis and calorimetry 59, no. 3 (2000): 935 942. https://doi.org/10.1023/A:1010186628054

[23] Silva, S., M. Conceiçăo, A. Souza, Shiva Prasad, M. Silva, V. Fernandes, A. Araújo, and F. Sinfrônio. "Thermal analysis of the powder and the bran of algaroba." Journal of thermal analysis and calorimetry 75, no. 2 (2004): 411-417. https://doi.org/10.1023/B:JTAN.0000027127.96271.22

[24] Turmanova, S. Ch, S. D. Genieva, A. S. Dimitrova, and L. T. Vlaev. "Non-isothermal degradation kinetics of filled with rise husk ash polypropene composites." Express Polymer Letters 2, no. 2 (2008): 133-146. https://doi.org/10.3144/expresspolymlett.2008.18

[25] Vlaev, L. T., I. G. Markovska, and L. A. Lyubchev. "Kinetics compensation effect at thermal degradation of rice husk." Oxidation Communications 27, no. 2 (2004): 444-452.

[26] Al-Mulla, Adam. "Enthalpy-entropy compensation in polyester degradation reactions." International Journal of Chemical Engineering 2012 (2012): 1-8. https://doi.org/10.1155/2012/782346 